\title{
Influence of Thickness on the Photosensing Properties of Chemically Synthesized Copper Sulfide Thin Films
}

\author{
Abhiman Dattatray Dhondge ${ }^{1}$, Sunil Rameshgir Gosavi ${ }^{1 *}$, Narayani Madhukar Gosavi², \\ Chatur Pundlik Sawant ${ }^{3}$, Amar Maruti Patil4, Abhijeet Ravsaheb Shelke ${ }^{4}$, \\ Nishad Gopal Deshpande ${ }^{4^{*}}$ \\ ${ }^{1}$ C. H. C. Arts, S. G. P. Commerce, and B. B. J. P. Science College, Taloda, India \\ ${ }^{2}$ Government College of Engineering, Jalgaon, India \\ ${ }^{3}$ G. T. Patil College, Nandurbar, India \\ ${ }^{4}$ q-SpinTech \& Nanomaterials Laboratory, Department of Physics, Shivaji University, Kolhapur, India \\ Email: srgosavi.taloda@gmail.com, ${ }^{*}$ nicedeshpande@yahoo.co.in
}

Received 28 December 2014; accepted 18 January 2015; published 21 January 2015

Copyright (C) 2015 by authors and Scientific Research Publishing Inc.

This work is licensed under the Creative Commons Attribution International License (CC BY).

http://creativecommons.org/licenses/by/4.0/

(c) (†) Open Access

\begin{abstract}
We report here the influence of thickness on the photosensing properties of copper sulfide (CuS) thin films. The CuS films were deposited onto glass substrate by using a simple and cost effective chemical bath deposition method. The changes in film thickness as a function of time were monitored. The films were characterized using X-ray diffraction technique (XRD), field emission scanning electron microscopy (FE-SEM), optical measurement techniques and electrical measurement. $\mathrm{X}$-ray diffraction results indicate that all the CuS thin films have an orthorhombic (covellite) structure with preferential orientation along (113) direction. The intensity of the diffraction peaks increases as thickness of the film increases. Uniform deposition having nanocrystalline granular morphology distributed over the entire glass substrate was observed through FE-SEM studies. The crystalline and surface properties of the CuS thin films improved with increase in the film thickness. Transmittance (except for $210 \mathrm{~nm}$ thick $\mathrm{CuS}$ film) together with band gap values was found to decrease with increase in thickness. I-V measurements under dark and illumination condition show that the CuS thin films give a good photoresponse.
\end{abstract}

\section{Keywords}

Copper Sulfide (CuS), Chemical Bath Deposition (CBD), Thin Film, X-Ray Diffraction (XRD), Field Emission Scanning Electron Microscopy (FESEM), Photosensitivity

\footnotetext{
${ }^{*}$ Corresponding authors.
}

How to cite this paper: Dhondge, A.D., Gosavi, S.R., Gosavi, N.M., Sawant, C.P., Patil, A.M., Shelke, A.R. and Deshpande, N.G. (2015) Influence of Thickness on the Photosensing Properties of Chemically Synthesized Copper Sulfide Thin Films. World Journal of Condensed Matter Physics, 5, 1-9. http://dx.doi.org/10.4236/wjcmp.2015.51001 


\section{Introduction}

Semiconductor metal chalcogenide thin films have a potential application in the field of the energy storage, gas, and photo-sensing mechanism [1]-[4]. Their semiconducting nanocrystalline nature together with electronic and optical properties makes them highly suitable for various opto-electronic applications. Among the available metal chalcogenides, copper sulfide (CuS) is an important semiconducting material that has been widely used in the field of solar cells, photocatalysts, supercapacitors, gas sensor, etc. [5]-[8]. In recent years, efforts have been devoted to the formation of the complex structure and to control the valence state in copper based chalcogenide compounds. It is reported that CuS has five stable phases that exists at room temperature (RT). These are covellite $(\mathrm{CuS})$ in the sulphur-rich region, anilite $\left(\mathrm{Cu}_{1.75} \mathrm{~S}\right)$, digenite $\left(\mathrm{Cu}_{1.8} \mathrm{~S}\right)$, djurleite $\left(\mathrm{Cu}_{1.95} \mathrm{~S}\right)$, and chalcocite $\left(\mathrm{Cu}_{2} \mathrm{~S}\right)$ in the copper-rich region [5]. Among these, CuS (covellite) exhibits metal-like electrical conductivity and it also possesses near-ideal solar control characteristics. Notwithstanding to this, they even show easy current-conduction and charge-transfer mechanism [9]. During the last decade, preparation of the CuS thin film became commercialized due to its stable opto-electronic performance and was found to be a suitable candidate for the photosensitive devices [10], which could lead to next generation displays [11] as well as touch screens [12]. Moreover, all these applications are based upon the property of electrical conductivity, which is rather one of the significant properties found in CuS.

There are several reports found on synthesis and characterization of CuS thin films deposited by different physical as well as chemical methods. For instance, Yuan et al. [13] reported on thickness dependent CuS thin films and found that with lowering the thickness, the transmittance of CuS thin films became larger. In addition to this, they used these CuS thin films as front contact layers and found a photoelectric response. Bollero et al. [14] also studied the influence of thickness on the optical and electrical properties. Interestingly, they found that the opto-electronic properties of the films did not changed much even after storing the samples for a year under laboratory ambient conditions. Furthermore, Naşcu et al. [15] studied CuS films both in dark and under illumination and found that the electrical resistance values decreased with illumination. In another study done by Yildirim et al. [16] on CuS, they found that the films were photosensitive and the photosensitivity increased with increase in light intensity. Moreover, they even reported that after annealing of these CuS films, the photosensitivity drastically decreased as compared to the as-deposited CuS films.

Although large amount of literature is available on the CuS thin film, but little is found on CuS as photosensors. In addition to this, the influence of thickness on the photo-sensitive CuS thin film is not properly studied and explained. Therefore, considering all the above mentioned facts, here in the present study we report about the influence of the thickness on the physical as well as photo-sensor properties of p-type CuS thin films synthesized by the simple chemical bath deposition (CBD).

\section{Experimental Details}

\subsection{Preparation of the Glass Substrate}

The glass substrate of dimensions $75 \mathrm{~mm} \times 75 \mathrm{~mm} \times 1.10 \mathrm{~mm}$ was used for deposition of CuS thin film. Substrate were washed with double distilled water and boiled in chromic acid for 2 hours. Further they were washed with detergent and rinsed in acetone with ultrasonic treatment. This process is necessary for substrate cleaning, which creates nucleation centers required in thin film deposition.

\subsection{Preparation of CuS Thin Films}

CBD is simple and promising method used in CuS thin film preparation. It requires low processing temperature and possibility for large scale deposition. Copper sulphate $\left(\mathrm{CuSO}_{4} \cdot 5 \mathrm{H}_{2} \mathrm{O}\right)$ was used as a copper source and thiourea $\left(\mathrm{SC}\left(\mathrm{NH}_{2}\right)_{2}\right)$ as a sulphur source. Reaction bath contains $10 \mathrm{ml} 0.1 \mathrm{M} \mathrm{CuSO}_{4} \cdot 5 \mathrm{H}_{2} \mathrm{O}, 11 \mathrm{ml}$ of $25 \%$ aq. ammonia, $10 \mathrm{ml}$ of $0.1 \mathrm{M} \mathrm{SC}\left(\mathrm{NH}_{2}\right)_{2}$ in $100 \mathrm{ml}$ beaker and rest distilled water to make the volume $50 \mathrm{ml}$. The $\mathrm{pH}$ value was adjusted at 10, to get uniform thin films of CuS on glass substrates. By several trails, the preparative parameters are optimized, concentration of the reactant solutions (viz. $\mathrm{CuSO}_{4} \cdot 5 \mathrm{H}_{2} \mathrm{O}$ and $\left.\mathrm{SC}\left(\mathrm{NH}_{2}\right)_{2}\right) 0.1 \mathrm{M}$, and $\mathrm{pH}$ 10. The deposition was allowed to proceed at RT for different time durations. Hydroxyl ions are created by ammonia when it reacts with water. These ions make a reaction with thiourea and ionized sulphur is obtained. Due to attractive forces between positive and negative ions of copper $\left(\mathrm{Cu}^{2+}\right)$ and sulphur $\left(\mathrm{S}^{2-}\right)$, small cluster of $\mathrm{CuS}$ is formed. These clusters are directly nucleated on the substrate surface and there they grow into islands of 
the condensed phase. Such islands start to form layers consisting of the CuS molecules and CuS thin film gets deposited on the glass substrate surface. The process of nucleation and growth is schematically shown in the Figure 1. After deposition, the glass microslides were taken out from the bath, washed with de-ionised water to separate the loosely bounded CuS atoms, then dried in air. The films of various thicknesses were obtained by varying the deposition time. Deposited thin films of CuS were further studied for various properties. Depositions longer than 70 minutes resulted in peeling of the films from the glass substrates.

\subsection{Characterization of CuS Thin Films}

The CuS thin films were characterized for structural, morphological, optical and electrical properties. Thickness of CuS thin film is measured by Fizeau fringe technique in which, thickness of thin film is determined as a difference of measured position of interference fringe patterns. When light is incident on the substrate, reflection of light from the surface, interface of film and substrate occurs. Thereby, phase difference will be generated giving interference patterns. The obtained interference pattern can be used for thickness measurement using the following relation:

$$
\Delta=2 \times n \times d \times \cos \varphi
$$

where, $d$-thickness, $n$-refractive index, $\varphi$-refractive angle, $\Delta$-optical path difference.

X-ray diffraction (XRD) patterns of the film were recorded on a Bruker AXS, Germany (D8 Advanced) diffractometer in the scanning range $20^{\circ}-80^{\circ}(2 \theta)$ using $\mathrm{CuK} \alpha$ radiations with wavelength $0.15405 \mathrm{~nm}$. S-48500 Type-II (HITACHI HIGH TECHNOLOGY CORPORATION Tokyo, Japan) field emission scanning electron microscope (FESEM) was used for the determination of surface morphology. Using JASCO UV-VIS spectrometer (V-630) the optical properties of CuS thin film were investigated by estimating the absorbance and transmittance relation with wavelength having range $400 \mathrm{~nm}-800 \mathrm{~nm}$. The I-V characteristics were studied using Keithley meter (Model No. 2400), over the range from $\pm 2 \mathrm{~V}$.

\section{Result and Discussion}

\subsection{Structural Analysis}

Figure 2 shows the XRD pattern of CuS thin films of different thickness deposited onto glass substrate. XRD pattern revealed that the CuS thin films are polycrystalline in nature with orthorombic (covellite) crystal structure when matched with JCPDS card No. 78-2122. XRD pattern of the CuS thin films showed sharp peak (113) along with other minor peaks corresponding to (112) and (115) planes. Apart from this a diffraction peak corresponding to $2 \theta=38.77^{\circ}$ was observed, which is a peak arising due to $\mathrm{Cu}(\mathrm{OH})_{2}$ (JCPDS card No. 00-003-0307). Such a phase may originate during the hydrolysis process of $\mathrm{Cu}^{2+}$, which was carried out at RT. Although there is presence of $\mathrm{Cu}(\mathrm{OH})_{2}$, it is found that the crystal structure of $\mathrm{CuS}$ has not been much affected. Moreover, the

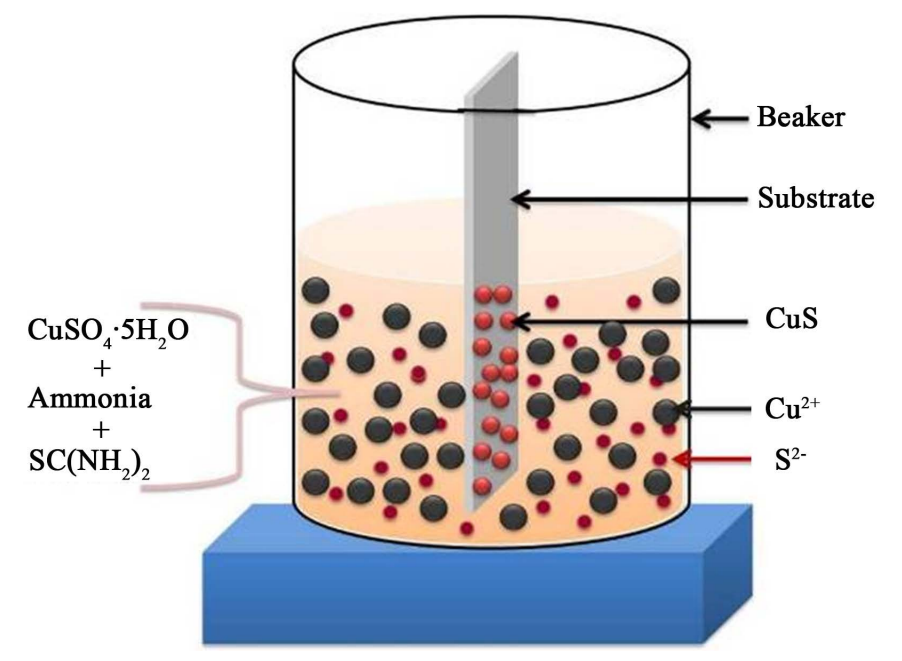

Figure 1. Schematic diagram of the chemical synthesis of CuS thin film. 


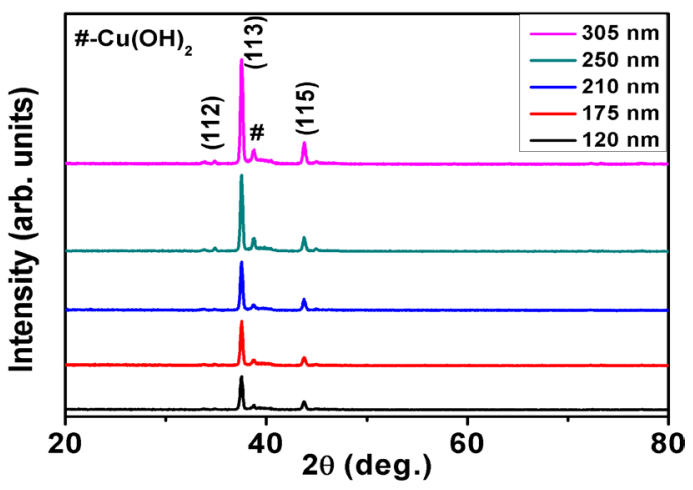

Figure 2. XRD patterns of CuS thin films deposited with different thickness.

presence of a number of peaks corresponding to CuS indicates that the films are polycrystalline with preferred orientation along (113) plane. It was also seen from the XRD pattern that the intensity of the peak increases with increase in thickness, while no significant shift in the peak position was observed. In fact there is a near-linear dependence of (113) peak intensity with respect to thickness found (see Figure 3). This is quite natural due the fact that with increase in thickness there increases the density of CuS material. For the high intense peak i.e., (113) plane, we calculated the crystallite size using Scherrer's formula as given below,

$$
D=\frac{k \lambda}{\beta \cos \theta}
$$

where: $\lambda$ is wavelength of $\mathrm{X}$-ray; $\beta$ is broadening of diffraction line measured at full width at half of the peak maxima in radians; $k$ is a constant (0.94) and $\theta$ is Bragg's angle. We found that the crystallite size ranges between 30 - $34 \mathrm{~nm}$ for all the samples, while there was no specific dependence found with respect to thickness.

\subsection{Surface Morphology and Compositional Analysis}

Figures 4(a)-(e) show the FESEM images for different thickness of CuS thin film. It is observed from these images that all the CuS thin films have uniform distribution of grains over the surface and mostly these grains fall in nanometer regime. When thickness of the film increases, morphology turned from tiny nanoparticle-like to heavy granules. Furthermore some CuS nanorods were found at Figure 4(a). Considering these, it is very likely that the CuS nanoparticles were nucleated and grown at low thickness and further started to agglomerate to form larger granules with progress of chemical deposition as is seen in the Figures 4(a)-(e). Significantly, microscopic defects like voids, pinholes or peeling are not observed. It can be seen that the thin film deposited at RT is uniform, dense and well adhered to the glass substrate. This kind of dense and compact morphology is essential for the applications of thin film solar cells. Since the leakage of photo-current can be prevented [17]. Higher magnification FESEM image of CuS thin film corresponding to $305 \mathrm{~nm}$ thickness indicated that the deposited film is uniformly covered with compact globular structures composed of spherical particles as shown in inset of Figure 4(e). The average diameter of the globule is less than $150 \mathrm{~nm}$ as compared with the diameter of the spherical particles ( 25 - $50 \mathrm{~nm}$ ), by which the globules are made.

\subsection{Optical Analysis}

The transmittance spectra of deposited CuS thin films having different thicknesses are shown in Figure 5. It is seen from Figure 5 that the transmittance edge gets shifted toward the longer wavelength, while there is decrease in transmittance (except for $210 \mathrm{~nm}$ thickness CuS film after $650 \mathrm{~nm}$ wavelength) with the increase in thickness of the CuS thin film. The shifting in the edge may occur due to the diffraction losses appeared as a result of agglomeration of the film thickness. This might also result in change of the refractive index of the material that may vary between the mean values [18]. Further to obtain the band gap values, we used the theory of optical absorption, which gives the relation between the absorption coefficient " $\alpha$ " and the photon energy " $h v$ ", for direct allowed transition as [19], 


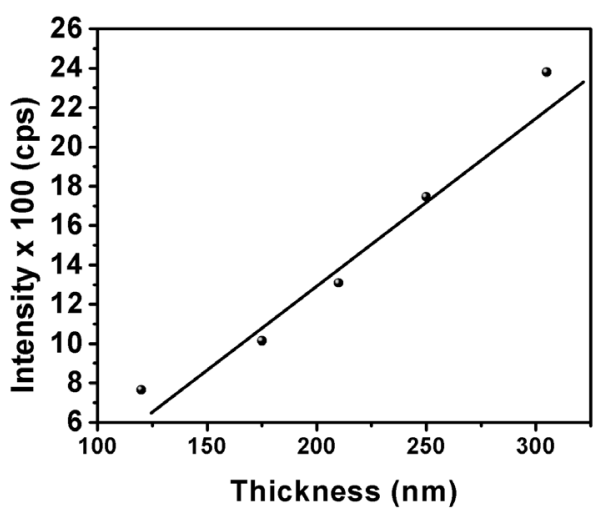

Figure 3. XRD peak intensities for (113) plane of CuS thin films with respect to film thickness. Note: The line used is to show near-linear dependence.
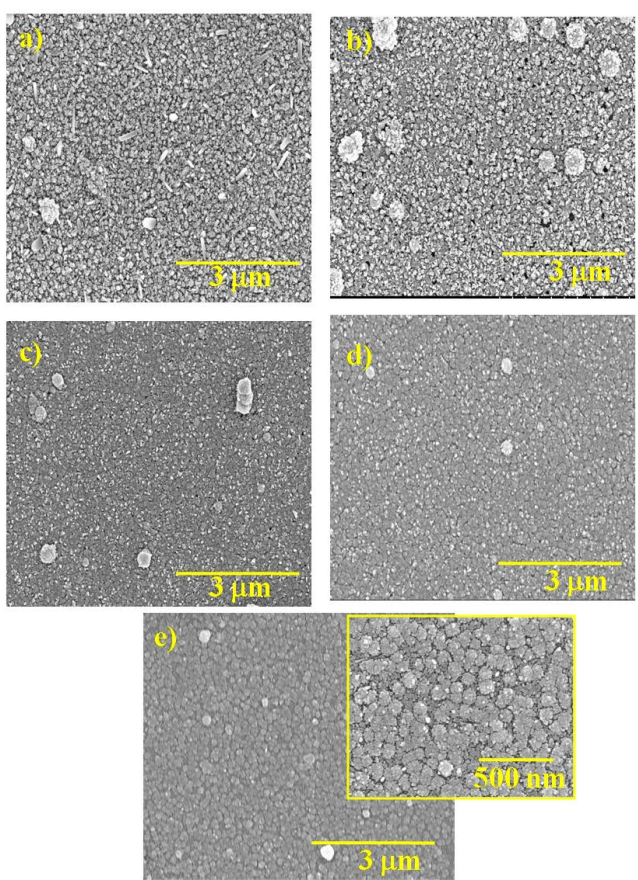

Figure 4. FESEM images of CuS thin films of different thickness on glass substrate: (a) 120 nm; (b) $175 \mathrm{~nm}$; (c) $210 \mathrm{~nm}$; (d) $250 \mathrm{~nm}$; and (e) $305 \mathrm{~nm}$ (inset of Figure 3(e) shows the higher magnification FESEM image).

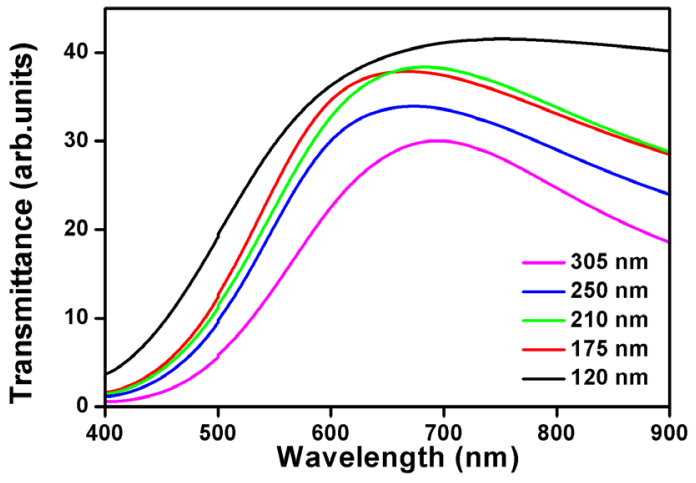

Figure 5. Transmittance spectra of CuS thin films of different thickness on glass substrate. 


$$
\alpha=\frac{A\left(h v-E_{g}\right)^{2}}{h v}
$$

where " $h v$ " is the photon energy, " $E_{g}$ " is the optical band gap, " $A$ " is a constant.

Using the above relation, we calculated $(\alpha h v)^{2}$ and $h v$ values, which is plotted as shown in Figure 6. After extrapolation of the linear portion to the energy axis i.e., $\mathrm{x}$-axis, will yield the optical band gap value of the material. The optical band gap value $E_{g}$ calculated is found to be decreased from $2.56 \mathrm{eV}$ to $2.42 \mathrm{eV}$ with the increase in the thickness of CuS thin films i.e., from $120 \mathrm{~nm}$ to $305 \mathrm{~nm}$, respectively. This may be due to the strong quantum confinement occurring along the thickness direction, so the geometric parameter in CuS enables to reduce the optical band gap in two dimensional quantum controls with high degree of precession [20]. This indicates that the thickness has a strong dependence i.e., inverse dependence on the optical bang gap value of the CuS thin film.

\subsection{Photosensitivity Studies}

Study of I-V characterization is done in dark and by varying illumination intensities of light onto different thickness CuS thin films [see Figures 7(a)-(e)]. For studying the photosensor properties, an area of $1 \mathrm{~cm}^{2}$ of CuS thin film were selected and silver paste was applied (two Ag contacts separated by a distance of $1 \mathrm{~cm}$ ) to ensure the good neutral electrical contact. Before light illumination, the I-V curve in dark was measured and then subsequently after light illumination (having different intensities) the corresponding I-V curve was measured. It was seen from all the I-V curves [see Figures 7(a)-(e)], that there is a linear dependence between I-V characteristics indicating ohmic nature of the CuS thin films. Furthermore, a general trend for all CuS samples showed that with increase in the illumination intensity, the photoresistance decreases (see Figure 8). This suggests that the increase in the incident photon energy breaks some of the covalent bonds in the CuS semiconductor and as a result generates free electron-hole pairs (EHP), which becomes available for current conduction thereby decreasing the resistance [21] [22]. Notwithstanding to this, it was also found that the increase in thickness of the CuS films, decreases the photoresistance values (see Figure 8). Significantly, it was observed for CuS films of $210 \mathrm{~nm}$ thickness that there is an uneven change in the photoresistance value with increase in the illumination intensity (see the orange square indicated in inset of Figure 8). As such with illumination of 5800 Lux intensity, the photoresistance was found to be increased and later it again started to decrease with increase in intensity. These uneven changes of the photoresistance with illumination intensity can be a direct consequence of the transmittance properties seen for this particular film. The transmittance was suddenly increased for this film as compared to other thickness films, indicating that at certain value of illuminated light intensity the films becomes transparent to the light and the possible EHP is hindered thereby causing an increase in the photoresistance values. This study suggests that though the light illumination intensity can increase the number of EHPs; but one can possibly have control over this number by simply controlling the thickness of the CuS thin film. In addition, it indicates the suitability of CuS thin films as smart photosensor devices.

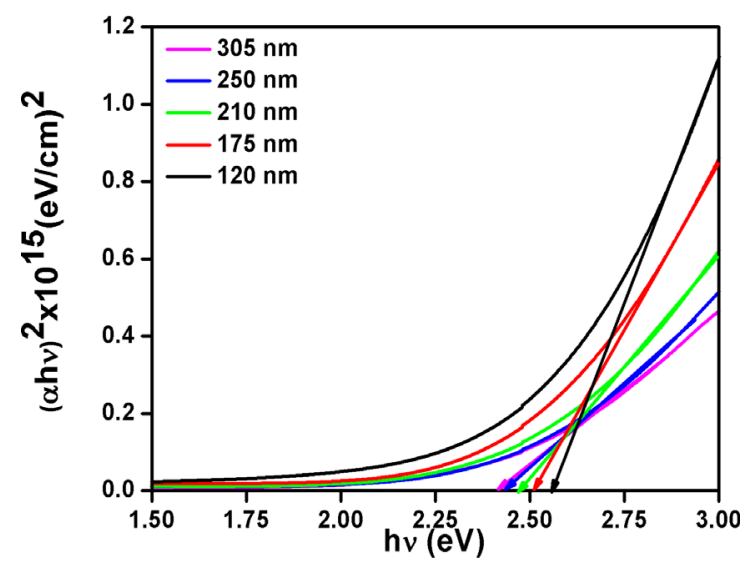

Figure 6. Plot of $(\alpha h v)^{2}$ versus $h v$ for CuS thin films of different thicknesses. 


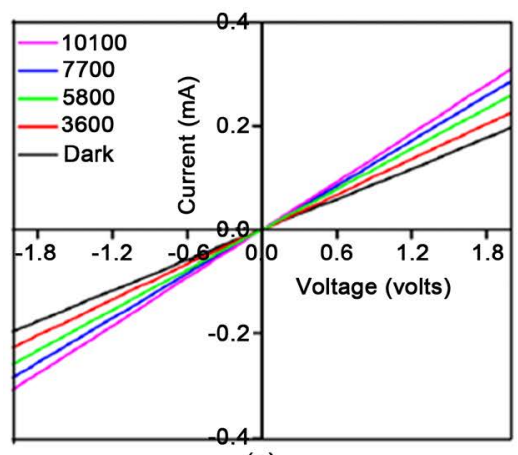

(a)

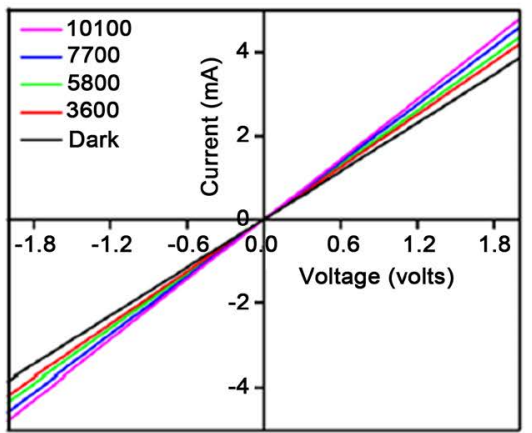

(c)

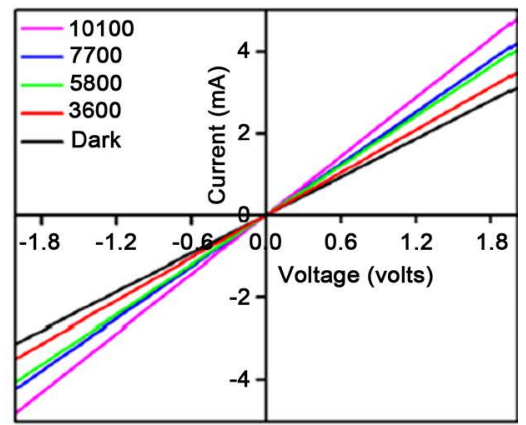

(b)

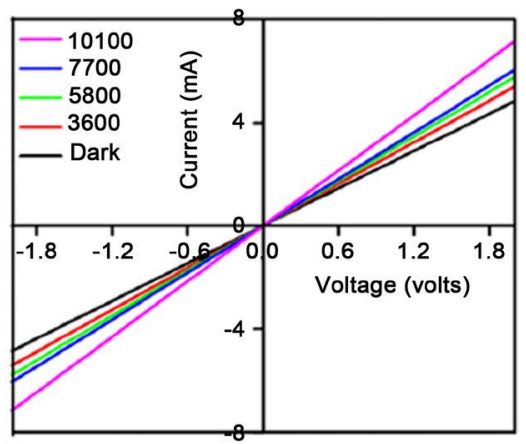

(d)

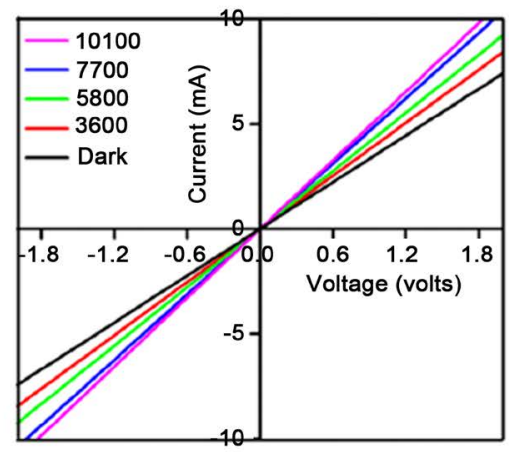

(e)

Figure 7. Current-voltage (I-V) characteristics curve for CuS thin film taken in dark as well as with different illumination intensities for: (a) $120 \mathrm{~nm}$; (b) $175 \mathrm{~nm}$; (c) $210 \mathrm{~nm}$; (d) $250 \mathrm{~nm}$ and (e) $305 \mathrm{~nm}$.

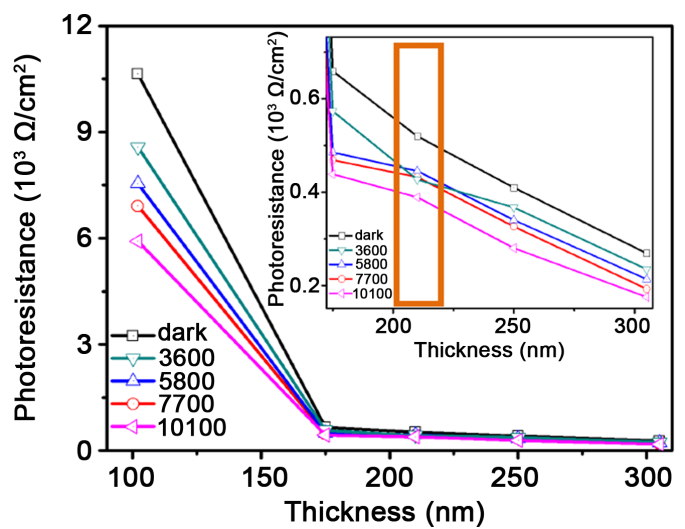

Figure 8. Plot of photo-resistance versus thickness taken at different illumination intensities. Inset shows the magnified view, while the orange square indicates the uneven variation of photoresistance for particular $210 \mathrm{~nm}$ CuS thick films. 


\section{Conclusion}

CuS thin films with different thickness have been successfully deposited by the simple and cost-effective chemical bath deposition technique. Increase in the thickness of the CuS films increased the crystallinity as well as morphological properties. Dense morphology with globular structures was confirmed for the large thickness CuS samples. Uneven changes in the transmittance helped us to understand the photo-resistance properties of the CuS thin films. Significant influence of the thickness on the photoresistance values was confirmed indicating that one could manipulate the photoresistance by simply controlling the thickness of the CuS thin films.

\section{Acknowledgements}

The authors are thankful to Head, UDCT Department, North Maharashtra University Jalgaon and Principal, Dr. P. V. Ramaiah, C. H. C. Arts, S. G. P. Commerce, and B. B. J. P. Science College, Taloda, for providing the laboratory facilities. SRG thank Chairman and Management members of Arts and Commerce College Trusts for constant encouragement for doing research work. NGD thanks Department of Science and Technology (DST) for awarding DST Inspire Faculty Award [IFA-PH-61/01/08/2013].

\section{References}

[1] Rezig, B., Duchemin, S. and Guastavino, F. (1979) Evaporated Layers of Cuprous Sulfides: Technology and Methods of Characterization. Solar Energy Materials, 2, 53-67. http://dx.doi.org/10.1016/0165-1633(79)90030-3

[2] Sadekar, H.K., Deshpande, N.G., Gudage, Y.G., Ghosh, A., Chavhan, S.D., Gosavi, S.R. and Sharma, R. (2008) Growth, Structural, Optical and Electrical Study of ZnS Thin Films Deposited by Solution Growth Technique (SGT). Journal of Alloys \& Compounds, 453, 519-524. http://dx.doi.org/10.1016/j.jallcom.2007.10.123

[3] Lenggoro, I.W., Kang, Y.C., Komiya, T., Okuyama, K. and Tohge, N. (1998) Formation of Submicron Copper Sulfide Particles Using Spray Pyrolysis Method. Japanese Journal of Applied Physics, 37, L288-L290. http://dx.doi.org/10.1143/JJAP.37.L288

[4] Ahire, R.R., Deshpande, N.G., Gudage, Y.G., Sagade, A.A., Chavhan, S.D., Phase, D.M. and Sharma, R. (2007) A Comparative Study of the Physical Properties of CdS, $\mathrm{Bi}_{2} \mathrm{~S}_{3}$ and Composite CdS- $\mathrm{Bi}_{2} \mathrm{~S}_{3}$ Thin Films for Photosensor Application. Sensors and Actuators A: Physical, 140, 207-214. http://dx.doi.org/10.1016/j.sna.2007.06.039

[5] Wu, C., Zhang, Z., Wu, Y., Lv, P., Nie, B., Luo, L., Wang, L., Hu, J. and Jie, J. (2013) Flexible CuS Nanotubes-ITO Film Schottky Junction Solar Cells with Enhanced Light Harvesting by Using an Ag Mirror. Nanotechnology, 24, Article ID: 045402. http://dx.doi.org/10.1088/0957-4484/24/4/045402

[6] Zhang, Y., Tian, J., Li, H., Wang, L., Qin, X., Asiri, A., Youbi, A.A. and Sun, X. (2012) Biomolecule-Assisted, Environmentally Friendly, One-Pot Synthesis of CuS/Reduced Graphene Oxide Nanocomposites with Enhanced Photocatalytic Performance. Langmuir, 28, 12893-12900. http://dx.doi.org/10.1021/la303049w

[7] Peng, H., Ma, G., Sun, K., Mu, J., Wanga, H. and Lei, Z. (2014) High-Performance Supercapacitor Based on MultiStructural CuS@Polypyrrole Composites Prepared by in Situ Oxidative Polymerization. Journal of Materials Chemistry A, 2, 3303-3307. http://dx.doi.org/10.1039/c3ta13859c

[8] Xu, J., Zhang, J., Yao, C., Dong, H. and Chil, J. (2013) Synthesis of Novel Highly Porous CuS Golf Balls by Hydrothermal Method and Their Application in Ammonia Gas Sensing. Journal of the Chilean Chemical Society, 58, 17221724. http://dx.doi.org/10.4067/S0717-97072013000200017

[9] Froment, M., Cachet, H., Essaaidi, H., Maurin, G. and Cortes, R. (1997) Metal Chalcogenide Semiconductors Growth from Aqueous Solutions. Pure and Applied Chemistry, 69, 77-82. http://dx.doi.org/10.1351/pac199769010077

[10] Dong, H.L., Zhu, H.F., Meng, Q., Gong X. and Hu, W.P. (2012) Supramolecular Polymers Constructed by Crown Ether-Based Molecular Recognition. Chemical Society Review, 41, 1621-1636. http://dx.doi.org/10.1039/c1cs15220c

[11] Fattal, D., Peng, Z., Tran, T., Vo, S., Fiorentino, M., Brug, J. and Beausoleil, R.G. (2013) A Multi-Directional Backlight for a Wide-Angle, Glasses-Free Three-Dimensional Display. Nature, 495, 348-351. http://dx.doi.org/10.1038/nature11972

[12] Lee, J.K., Kim, S.S., Park, Y.I., Kim, C.D. and Hwang, Y.K. (2011) In-Cell Adaptive Touch Technology for a Flexible e-Paper Display. Solid-State Electronics, 56, 159-162. http://dx.doi.org/10.1016/j.sse.2010.10.008

[13] Yuan, K.D., Wu, J.J., Liu, M.L., Zhang, L.L., Xu, F.F., Chen, L.D. and Huang, F.Q. (2008) Fabrication and Microstructure of $p$-Type Transparent Conducting CuS Thin Film and Its Application in Dye-Sensitized Solar Cell. Applied Physics Letters, 93, Article ID: 132106.

[14] Bollero, A., Grossberg, M., Asenjo, B. and Gutiérrez, M.T. (2009) CuS-Based Thin Films for Architectural Glazing Applications Produced by Co-Evaporation: Morphology, Optical and Electrical Properties. Surface and Coatings 
Technology, 204, 593-600. http://dx.doi.org/10.1016/j.surfcoat.2009.08.037

[15] Naşcu, C., Pop, I., Ionescu, V., Indrea, E. and Bratu, I. (1997) Spray Pyrolysis Deposition of CuS Thin Films. Materials Letters, 32, 73-77. http://dx.doi.org/10.1016/S0167-577X(97)00015-3

[16] Ali Yildirim, M., Ates, A. and Astam, A. (2009) Annealing and Light Effect on Structural, Optical and Electrical Properties of CuS, CuZnS and ZnS Thin Films Grown by the SILAR Method. Physica E, 41, 1365-1372. http://dx.doi.org/10.1016/j.physe.2009.04.014

[17] Gao, C., Shen, H., Sun, L. and Shen, Z. (2011) Chemical Bath Deposition of $\mathrm{Bi}_{2} \mathrm{~S}_{3}$ Films by a Novel Deposition System. Applied Surface Science, 257, 7529-7533. http://dx.doi.org/10.1016/j.apsusc.2011.03.080

[18] Lee, S.H., Leem, J.W. and Yu, J.S. (2013) Transmittance Enhancement of Sapphires with Antireflective Subwavelength Grating Patterned UV Polymer Surface Structures by Soft Lithography. Optics Express, 21, 29298-29303. http://dx.doi.org/10.1364/OE.21.029298

[19] Gosavi, S.R., Deshpande, N.G., Gudage, Y.G. and Sharma, R. (2008) Physical, Optical and Electrical Properties of Copper Selenide (CuSe) Thin Films Deposited by Solution Growth Technique at Room Temperature. Journal of Alloys and Compounds, 448, 344-348. http://dx.doi.org/10.1016/j.jallcom.2007.03.068

[20] Budiman, M.F., Hu, W., Igarashi, M., Tsukamoto, R., Isoda, T., Itoh, K.M., Yamashita, I., Murayama, A., Okada, Y. and Samukawa, S. (2012) Control of Optical Bandgap Energy and Optical Absorption Coefficient by Geometric Parameters in Sub-10 nm Silicon-Nanodisc Array Structure. Nanotechnology, 23, Article ID: 065302.

[21] Oladeji, I.O. and Chow, L. (1997) Optimization of Chemical Bath Deposited Cadmium Sulfide Thin Films. Journal of the Electrochemical Society, 144, 2342-2346. http://dx.doi.org/10.1149/1.1837815

[22] Seghaier, S., Kamoun, N., Brini, R. and Amara, A.B. (2006) Structural and Optical Properties of PbS Thin Films Deposited by Chemical Bath Deposition. Materials Chemistry and Physics, 97, 71-80.

http://dx.doi.org/10.1016/j.matchemphys.2005.07.061 
Scientific Research Publishing (SCIRP) is one of the largest Open Access journal publishers. It is currently publishing more than 200 open access, online, peer-reviewed journals covering a wide range of academic disciplines. SCIRP serves the worldwide academic communities and contributes to the progress and application of science with its publication.

Other selected journals from SCIRP are listed as below. Submit your manuscript to us via either submit@scirp.org or Online Submission Portal.
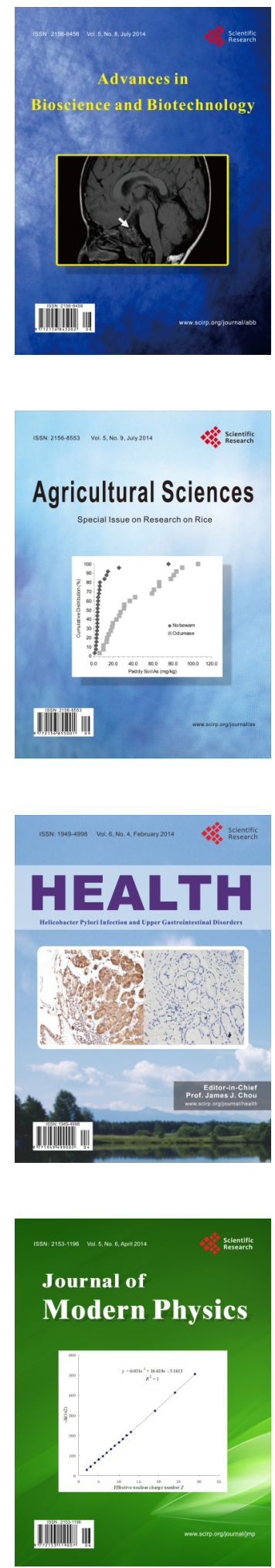
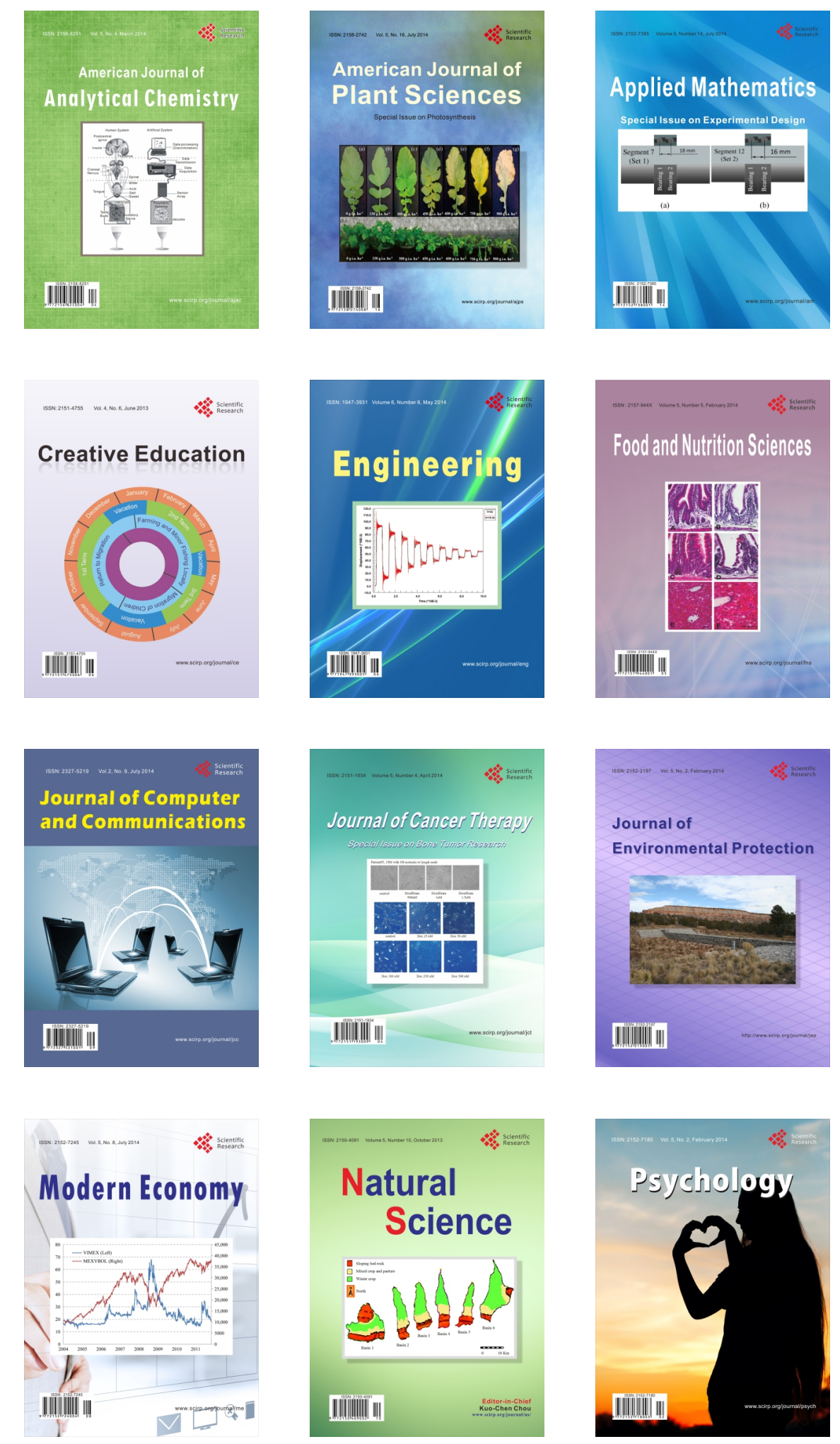